\title{
Abruptio placentae: impact of early treatment on maternal and fetal outcomes
}

\author{
Shikha P. Mehta*, Prasad Y. Deshmukh, Amarjeet K. Bawa
}

Department of Obstetrics and Gynecology, LTMMC and GH, Mumbai, Maharashtra, India

Received: 22 January 2021

Accepted: 01 March 2021

\section{*Correspondence:}

Dr. Shikha P. Mehta,

E-mail: shikham312@gmail.com

Copyright: (c) the author(s), publisher and licensee Medip Academy. This is an open-access article distributed under the terms of the Creative Commons Attribution Non-Commercial License, which permits unrestricted non-commercial use, distribution, and reproduction in any medium, provided the original work is properly cited.

\begin{abstract}
Background: Haemorrhage is the leading cause for maternal mortality in India as well as the world. Abruptio placenta is the second most common cause of antepartum haemorrhage and it is associated with sudden, severe and devastating maternal and fetal complications. The main objective of this study is to study the impact of early treatment on maternal and fetal outcomes.

Methods: This single center retrospective study includes all patients admitted at Lokmanya Tilak Municipal General Hospital, a tertiary referral hospital, diagnosed to have abruptio placenta (grade II and grade III) from 01 July 2019 to 31 December 2019. In this study a total of 48 cases were included and data regarding time duration between onset of symptoms and initiation of treatment, clinical course and maternal and fetal outcomes was noted.

Results: A total of 5059 deliveries occurred over six months. The incidence of placental abruption was found to be $0.94 \%$. Patients receiving early care (30 cases, $62.5 \%)$ were found to have significantly better maternal outcomes ( $\mathrm{p}=0.006$, Chi square test) as well as fetal outcomes ( $\mathrm{p}=0.007$, Fischer's exact test) than patients who received delayed care (18 cases, $37.5 \%)$.

Conclusions: Abruptio placentae is an obstetric emergency and early diagnosis as well as initiation of treatment plays an important role in curbing complications. Strengthening of peripheral centers, availability of multi-disciplinary approach and educating health care staff as well as patients form the cornerstones of improved maternal and fetal outcomes.
\end{abstract}

Keywords: Placental abruption, Antepartum haemorrhage, Early intervention, Outcomes

\section{INTRODUCTION}

In India, every twenty minutes, a woman dies due to complications related to pregnancy or childbirth. ${ }^{1}$ Haemorrhage is the leading cause of maternal morbidity and mortality in India as well as the world. Antepartum haemorrhage complicates $3-5 \%$ of pregnancies worldwide. ${ }^{2}$ Two important causes are placenta previa and abruptio placentae.

Placental abruption is the premature separation of a normally situated placenta from the uterine wall, resulting in haemorrhage before the delivery of the fetus. Worldwide, it complicates $1 \%$ of all pregnancies. ${ }^{3}$
However in India, the incidence has been found to be as high as $5 \% .^{4}$

Recently, a few predictive factors have come to light. They include subchorionic hematoma on ultrasonography (USG) in early pregnancy, pregnancy associated plasma protein A below $5^{\text {th }}$ percentile at the time of $1^{\text {st }}$ trimester, unexplained alpha feto protein elevation $>2 \mathrm{MOM}$ on second trimester screening. ${ }^{5}$ Angiotensinogen Thr 235 mutation, which is associated with abnormal remodelling of uterine artery spiral arterioles and associated with preecclampsia as well as placental abruption. ${ }^{6}$ An elevated resistance index, pulsatility index or the presence of a notch in uterine artery blood flow in first and second 
trimester uterine artery Doppler ultrasonography can have a role in prediction of abruption. ${ }^{7}$

It typically presents with a triad of abdominal pain, abnormal uterine tenderness, and vaginal bleeding after the $20^{\text {th }}$ week of pregnancy. Imaging modalities like ultrasonography can be employed to aid diagnosis, however various studies show that ultrasonography only diagnoses $50 \%$ of clots. ${ }^{8}$

The clinical grading suggested by Sher and Statland is of prognostic importance - grade I: asymptomatic, diagnosed after delivery by finding retroplacental clot on placenta; grade II: classic signs of abruption present but without maternal or fetal distress; and grade III: severe abruption with dead fetus without coagulopathy and with coagulopathy. ${ }^{9}$

The major complications are hemorrhagic shock, disseminated intravascular coagulation, ischemic necrosis of the distal organs (especially kidneys and brain) and postpartum haemorrhage. Placental abruption can lead to initiation of coagulation cascade and DIC. The inciting event is tissue thromboplastin release into maternal circulation with subsequent microvascular coagulation. Fetal hypoxia and even fetal death can occur as placental disruption renders the involved placental surface inadequate for gas and metabolic exchange. Additionally disrupted maternal and fetal vascular channels may communicate, resulting in a potentially catastrophic fetal blood loss into maternal circulation, maternal $\mathrm{Rh}$ sensitisation or even fatal amniotic fluid embolism.

\section{METHODS}

This is a retrospective observational study carried out over a period of six months, from July 2019 to December 2019 in a major tertiary care teaching hospital in Mumbai. The study included patients who were admitted with the diagnosis Placental abruption of grade II and grade III by Sher and Statland's classification. This classification was chosen as for its relative objectivity and universal reproducibility.

Out of 5059 deliveries during this period, 65 women had placental abruption. 48 women had grade II and grade III placental abruption.17 cases had grade I abruption and were excluded from the study.

Detailed history regarding age, parity, booking status, referral status, pre-existing risk factors as well as general systemic and obstetric examination of the patients was compiled.

Records of initiation of definitive management and the time interval between diagnosis and initiation of intervention were studied, with the upper limit cut off for early intervention taken to be within 1 hour. Patients were accordingly grouped as having received early intervention and having received delayed intervention. Definitive intervention was taken to be initiation of correction of anaemia, thrombocytopenia, coagulation disorders, treatment of correctable risk factors and delivery. General supportive measures such as initiation of I.V. access, fluid replacement and oxygen therapy were not included as a part of definitive intervention.

Further, mode of delivery and clinical course was analysed, including duration of hospital stay, need for intensive care, blood transfusion, ventilatory support. Data regarding occurrence of complications such as end organ ischemic damage, shock, Post-partum haemorrhage, disseminated intravascular coagulation, puerperal sepsis, surgical site infection and obstetric hysterectomy was collected.

Maternal outcome was a dependent variable, based on duration of intensive care unit (ICU) stay (cut off $>2$ days) and presence of any complication of placental abruption.

Records of details of the babies like weight, Apgar score at 1 and 5 minutes, maturity, need for intensive care monitoring, duration of stay and morbidity and mortality were analyzed. Predictors of fetal outcome were considered to be duration of intensive care stay (cut off $>7$ days) and Agar score at 5 minutes.

\section{Statistical analysis}

Entry and cleaning of data was done using MS Excel software. Continuous variables were grouped into categorical data then summarized as proportions and analyzed by Chi-square, Fischer's exact test and odds ratio was calculated. $\mathrm{P}$ values of less than 0.05 were considered significant.

\section{RESULTS}

A total of 65 cases of abruption placentae were present out of 5059 deliveries at LTMMC and GH in a period of 6 months, from July 2019 to December 2019. The incidence of abruptio placentae in this study was found to be $1.2 \%$. 17 cases accounting for grade I placental abruption were excluded. 48 cases included in the study were of grade II and grade III abruption.

Table 1: Maternal age and parity.

\begin{tabular}{|ll|}
\hline Characteristics & $\begin{array}{l}\text { No. of patients } \\
\text { n }(\%)\end{array}$ \\
\hline Age (years) & \\
\hline$<20$ & $7(14.58)$ \\
\hline $21-25$ & $26(54.16)$ \\
\hline $26-30$ & $9(18.75)$ \\
\hline$>30$ & $6(12.5)$ \\
\hline Parity & $20(41.66)$ \\
\hline Primigravida & $24(50)$ \\
\hline Multigravida & $4(8.33)$ \\
\hline Grandmultipara $(>4)$ & \\
\hline
\end{tabular}


Maximum patients with placental abruption were between 21-25 years of age. There wasn't a significant difference between the incidence of abruption in multiparous and primiparous women.

Majority of patients receiving delayed care were patients transferred in from peripheral hospitals. Pre-ecclampsia, chronic hypertension and ecclampsia were collectively the most significant risk factor followed by preterm premature rupture of membranes.

Maximum patients from both categories were found to have grade II abruption. Of patients with grade III abruption, only $1(2.08 \%)$ patient who received immediate care was categorized as IIIa on account of intra uterine fetal death whereas $3(6.25 \%)$ patients who received delayed care had an intra-uterine fetal death, with 1 patient also having coagulopathy.
In most cases of grade II and III placenta abruption immediate delivery is indicted as reflected by $87.5 \%$ of patients requiring emergency lower segment caesarean section. Amongst patients requiring vaginal delivery 4 patients belonged to grade II abruption and 2 patients belonged to grade III.

Most patients presenting with abruption, whether early or late required blood transfusion in the form of packed red cells. Several patients required platelet and plasma transfusion for correction of coagulopathies. It is important to note that while transfusion of packed red cells was not statistically significant between patients receiving early and delayed care, platelet and plasma transfusion was found to be significantly higher ( $\mathrm{p}$ value $=0.001$, Chi square test) in patients receiving delayed care which may be due to the fact that patients receiving delayed care were more likely to have coagulopathy.

Table 2: Maternal parameters on admission.

\begin{tabular}{|c|c|c|c|}
\hline Parameters & Early intervention n (\%) & Delayed intervention $\mathbf{n}(\%)$ & Total n (\%) \\
\hline \multicolumn{4}{|l|}{ Booking status } \\
\hline Booked & $22(45.83)$ & 0 & $22(45.83)$ \\
\hline \multicolumn{4}{|l|}{ Un-booked } \\
\hline (1) Transferred & $7(14.58)$ & $17(35.41)$ & $24(50)$ \\
\hline (2) Unregistered & $1(2.08)$ & $1(2.08)$ & $2(4.16)$ \\
\hline \multicolumn{4}{|l|}{ Pre-existing risk factors } \\
\hline Prior abruption & $1(2.08)$ & 0 & $1(2.08)$ \\
\hline Previous caesarean section & $4(8.33)$ & $7(14.58)$ & $11(22.91)$ \\
\hline Thrombophilia & - & - & - \\
\hline \multicolumn{4}{|l|}{ Causative factors } \\
\hline Hypertensive disease & $21(43.75)$ & $13(27.08)$ & $34(70.83)$ \\
\hline Polyhydramnios & $1(2.08)$ & $3(6.25)$ & $4(8.33)$ \\
\hline Twins & $1(2.08)$ & 0 & $1(2.08)$ \\
\hline $\begin{array}{l}\text { Preterm premature rupture of } \\
\text { membranes }\end{array}$ & $3(6.25)$ & 8 (16.66) & $11(22.91)$ \\
\hline Malpresentation & 0 & $2(4.16)$ & $2(4.16)$ \\
\hline \multicolumn{4}{|l|}{ Grade } \\
\hline II & $29(60.41)$ & $15(31.25)$ & $44(91.67)$ \\
\hline IIIa & $1(2.08)$ & $2(4.16)$ & $3(6.25)$ \\
\hline IIIb & 0 & $1(2.08)$ & $1(2.08)$ \\
\hline \multicolumn{4}{|l|}{ Mode of delivery } \\
\hline Vaginal & $2(4.16)$ & $4(8.33)$ & $6(12.5)$ \\
\hline Lower segment caesarean section & $28(58.33)$ & $14(29.16)$ & $42(87.5)$ \\
\hline \multicolumn{4}{|l|}{ Hemoglobin on admission (gm\%) } \\
\hline$>9$ & $9(18.75)$ & $>9$ & $9(18.75)$ \\
\hline $7-9$ & $14(29.16)$ & $7-9$ & $14(29.16)$ \\
\hline $5-7$ & $6(12.5)$ & $5-7$ & $6(12.5)$ \\
\hline$<5$ & $1(2.08)$ & $<5$ & $1(2.08)$ \\
\hline \multicolumn{4}{|l|}{ Hemoglobin post-delivery (gm\%) } \\
\hline$>9$ & $6(12.5)$ & $>9$ & $6(12.5)$ \\
\hline $7-9$ & $11(22.91)$ & $7-9$ & $11(22.91)$ \\
\hline $5-7$ & $10(20.83)$ & $5-7$ & $10(20.83)$ \\
\hline$<5$ & $3(6.25)$ & $<5$ & $3(6.25)$ \\
\hline
\end{tabular}


Table 3: Type of components transfused.

\begin{tabular}{|ll|}
\hline Transfusion & Total patients $\mathbf{n}(\%)$ \\
\hline Packed red cells & $41(85.41)$ \\
\hline Platelets & $23(47.91)$ \\
\hline Fresh frozen plasma & $26(54.16)$ \\
\hline
\end{tabular}

Table 4: Comparison of level of care required (maternal).

\begin{tabular}{|llll|}
\hline $\begin{array}{l}\text { Post- } \\
\text { partum } \\
\text { care }\end{array}$ & $\begin{array}{l}\text { Early } \\
\text { intervention } \\
\mathrm{n}(\%)\end{array}$ & $\begin{array}{l}\text { Delayed } \\
\text { intervention } \\
\mathrm{n}(\%)\end{array}$ & $\begin{array}{l}\text { Total } \\
\mathrm{n}(\%)\end{array}$ \\
\hline $\begin{array}{l}\text { Ward } \\
\text { care }\end{array}$ & $6(12.5)$ & $1(2.08)$ & $\begin{array}{l}7 \\
(14.58)\end{array}$ \\
\hline $\begin{array}{l}\text { ICU care } \\
\text { <2 days }\end{array}$ & $11(22.91)$ & $3(6.25)$ & $\begin{array}{l}14 \\
(29.17)\end{array}$ \\
\hline $\begin{array}{l}\text { ICU care } \\
\text { >2 days }\end{array}$ & $13(27.08)$ & $14(29.16)$ & $\begin{array}{l}\text { (27 } \\
(56.25)\end{array}$ \\
\hline
\end{tabular}

Ward care and ICU care less than 2 days was significantly higher in cases receiving early intervention as compared to delayed intervention ( $\mathrm{p}$ value $=0.03$, Fischer's exact test). There was one maternal mortality due to abruption placenta accounting for $2.08 \%$ of the total cases. This single mortality was in a case of grade IIIa abruption, receiving delayed intervention, which proceeded to severe coagulopathy with acute kidney injury followed by irreversible shock with pulmonary oedema and cardiac collapse despite triple inotropic support.

The occurrence of post-partum haemorrhage, surgical site infections, purperal sepsis and obstetric hysterectomy was not significantly less in cases requiring early intervention as compared to delayed intervention. However, acute renal failure, shock, massive blood transfusions and coagulopathies were significantly more in patients receiving delayed intervention. Of the 9 patients who had post-partum haemorrhage, 1 patient required obstetric hysterectomy while 8 other patients were managed conservatively.

Amongst patients who went into shock, early reversible shock was found in the patient receiving early care as well as 4 patients receiving delayed care. Only 1 patient had late, irreversible shock and this was the same patient who accounted for the maternal mortality in this study as mentioned above.

Overall, 17 out of 30 patients with delayed intervention had none of these complications, as compared to 3 out of 18 patients receiving delayed intervention who did not have any of these complications. This was statistically significant. ( $p=0.007$, Fischer's exact test).

\section{Fetal parameters}

Of the total cases, $19(39.58 \%)$ cases were born between 32-36 weeks of gestation while $11(22.91 \%)$ cases were between 28-32 weeks of gestation. 5 (10.41\%) babies weighed $<1 \mathrm{~kg}$ at birth, while maximum babies, 23 (47.91\%) weighed between $1.5-2.5 \mathrm{~kg}$ at birth.

As delivery is indicated irrespective of gestational age in grade II and grade III of placental abruption, baby weight at birth and maturity were not considered to be indicators of fetal outcomes. Abruption is a risk factor predisposing to premature delivery. 2 cases of early and delayed intervention each were found to have fetal growth restriction.

Cases receiving delayed intervention were more likely to have APGAR scores $<7$ at 5 minutes than cases receiving early intervention $(\mathrm{OR}=7.7, \mathrm{CI}=1.808-33.04, \mathrm{P}=0.005)$. Of 8 cases with APGAR less than 3, 7 mortalities were noted and 1 baby had grade 3 hypoxic ischemic encephalopathy due to preterm birth.

ICU care $>7$ days was considered to be an indicator for poor fetal outcome and it was found to be statistically significant in cases receiving delayed care with $p$ value $=0.02$ (Fischer's exact test). Overall, babies born to mothers receiving early intervention had shorter intensive care unit stays and better APGAR scores compared to those born to mothers receiving delayed intervention. Perinatal mortality rate was found to be higher in cases receiving delayed intervention, 277.8 per 1000 as compared to cases receiving early intervention, 66.7 per 1000. Of the 3 neonatal deaths, 2 were due to complications arising from prematurity (gestational age $<32$ weeks) and 1 was due to acute respiratory distress syndrome (gestational age 32-36 weeks).

Table 5: Comparison of maternal outcomes.

\begin{tabular}{|lllll|}
\hline Maternal outcomes & Early intervention & Delayed intervention & Total $\mathbf{n}(\%)$ & P value \\
\hline Coagulopathy & 9 & 14 & $23(47.91)$ & $0.001^{* *}$ \\
\hline Acute renal failure & 1 & 6 & $7(14.58)$ & $0.008^{*}$ \\
\hline Shock & 1 & 5 & $6(12.5)$ & $0.008^{*}$ \\
\hline Obstetric hysterectomy & 0 & 1 & $1(2.08)$ & $0.3^{*}$ \\
\hline Postpartum haemorrhage & 5 & 4 & $9(18.75)$ & $0.7^{*}$ \\
\hline Massive blood transfusion & 2 & 6 & $8(16.66)$ & $0.03^{*}$ \\
\hline Surgical site infection & 1 & 2 & $3(6.25)$ & $0.5^{*}$ \\
\hline Puerperal sepsis & 1 & 1 & $2(4.16)$ & $1.0^{*}$ \\
\hline
\end{tabular}

*Fischer's exact test, ${ }^{* *}$ Chi square test 
Table 6: Comparison of incidence of complications between 2 groups.

\begin{tabular}{|lllll|}
\hline Maternal complication & $\begin{array}{l}\text { Early intervention } \\
\mathbf{n}(\%)\end{array}$ & $\begin{array}{l}\text { Delayed intervention } \\
\mathbf{n}(\%)\end{array}$ & $\begin{array}{l}\text { Total } \\
\mathbf{n}(\%)\end{array}$ & P value \\
\hline None & $17(35.41)$ & $3(6.25)$ & $20(41.66)$ & 0.006 \\
\hline One or more & $13(27.08)$ & $15(33.33)$ & $28(58.33)$ & \\
\hline
\end{tabular}

Table 7: Comparison of fetal parameters at birth.

\begin{tabular}{|llll|}
\hline Fetal parameters & $\begin{array}{l}\text { Early intervention } \\
\mathbf{n}(\%)\end{array}$ & $\begin{array}{l}\text { Delayed intervention } \\
\mathbf{n}(\%)\end{array}$ & $\begin{array}{l}\text { Total } \\
\mathbf{n}(\%)\end{array}$ \\
\hline Gestational age at birth (weeks) & $7(14.58)$ & $4(8.33)$ & $11(22.91)$ \\
\hline $28-32$ & $13(27.08)$ & $6(12.5)$ & $19(39.58)$ \\
\hline $32-36$ & $10(20.83)$ & $8(16.66)$ & $18(37.5)$ \\
\hline$>36$ & & & $5(10.41)$ \\
\hline Fetal weight at birth $(\mathbf{k g )}$ & $3(6.25)$ & $2(4.16)$ & $6(12.5)$ \\
\hline$<1$ & $4(8.33)$ & $2(4.16)$ & $23(47.91)$ \\
\hline $1-1.5$ & $15(33.33)$ & $8(16.66)$ & $14(29.16)$ \\
\hline $1.5-2.5$ & $8(16.66)$ & $6(12.5)$ & $26(54.16)$ \\
\hline$>2.5$ & & & $22(45.83)$ \\
\hline Sex & $18(37.5)$ & $8(16.66)$ & $10(20.82)$ \\
\hline Male & $12(25)$ & $10.53)$ \\
\hline Female & & \\
\hline
\end{tabular}

Table 8: Comparison of Apgar scores.

\begin{tabular}{|lllllll|}
\hline & $\mathbf{7}$ to $\mathbf{1 0}$ & & $\mathbf{4}$ to $\mathbf{7}$ & & $\mathbf{0}$ to $\mathbf{3}$ & \\
APGAR & $\begin{array}{l}\text { Early } \\
\text { intervention } \\
\text { score }\end{array}$ & $\begin{array}{l}\text { Delayed } \\
\text { intervention } \\
\mathbf{n}(\boldsymbol{\%})\end{array}$ & $\begin{array}{l}\text { Early } \\
\text { intervention } \\
\mathbf{n}(\boldsymbol{\%})\end{array}$ & $\begin{array}{l}\text { Delayed } \\
\text { intervention } \\
\mathbf{n}(\boldsymbol{\%})\end{array}$ & $\begin{array}{l}\text { Early } \\
\text { intervention } \\
\mathbf{n}(\boldsymbol{\%})\end{array}$ & $\begin{array}{l}\text { Delayed } \\
\text { intervention } \\
\mathbf{n}(\boldsymbol{\%})\end{array}$ \\
\hline $\mathbf{1}$ minute & $15(33.33)$ & $2(4.16)$ & $13(27.08)$ & $11(22.91)$ & $2(4.16)$ & $5(10.41)$ \\
\hline $\mathbf{5}$ minute & $17(35.41)$ & $3(6.25)$ & $11(22.91)$ & $10(20.83)$ & $2(4.16)$ & $5(10.41)$ \\
\hline
\end{tabular}

Table 9: Comparison of level of care required (fetal).

\begin{tabular}{|llll|}
\hline Level of care & $\begin{array}{l}\text { Early intervention } \\
\mathbf{n}(\%)\end{array}$ & $\begin{array}{l}\text { Delayed intervention } \\
\mathbf{n}(\%)\end{array}$ & $\begin{array}{l}\text { Total } \\
\mathbf{n}(\%)\end{array}$ \\
\hline Baby with mother $($ ward care) & $12(25)$ & $2(4.16)$ & $14(21.16)$ \\
\hline ICU care $<7$ days & $5(10.41)$ & $2(4.16)$ & $7(14.58)$ \\
\hline ICU care $>$ 7 days & $10(20.83)$ & $11(22.91)$ & $21(43.75)$ \\
\hline
\end{tabular}

Table 10: Comparison of maternal and perinatal mortality.

\begin{tabular}{|llll|}
\hline Mortality & Early intervention $\mathbf{n}(\%)$ & Delayed intervention $\mathbf{n}(\%)$ & Total $\mathbf{n}(\%)$ \\
\hline Maternal & 0 & $1(2.08)$ & $1(2.08)$ \\
\hline NND & $1(2.08)$ & $2(4.16)$ & $3(6.25)$ \\
\hline IUFD & $1(2.08)$ & $3(6.25)$ & $4(8.33)$ \\
\hline
\end{tabular}

\section{DISCUSSION}

Abruptio placentae can occur over a large spectrum of symptoms ranging from minimum vaginal bleeding that can be missed to devastatingly severe complications like shock, coagulopathy and end organ damage. Overall, globally it is associated with poor maternal as well as fetal outcomes. The incidence of placental abruption at our center was found to be $0.94 \%$, which is comparable to the overall incidence of placental abruption which is $0.4-1 \%$, with more incidence found in developing countries compared to developed countries. ${ }^{10}$

In our study we took the cut off for delayed intervention as $>1$ hour from diagnosis as it is the upper limit by which lab reports can be traced, blood and blood products can be issued and transfused with the definitive management of delivery initiated. This is a stricter criteria as compared to a study by Knab et al which demonstrated that approximately $75 \%$ of fetal deaths occurred more than 90 
minutes after admission to the hospital and almost $70 \%$ of all perinatal mortality occurred in infants who were delivered more than 2 hours from the time of diagnosis. However, studies conducted by Hillemanns et al in 1996 in Germany have shown that a mean decision to delivery interval of 12.8 minutes with the $90^{\text {th }}$ centile of 22 minutes is achievable.

Only grade II and grade III cases were included as grade I placental abruption can be given expectant management with intensive monitoring and hence the impact of immediate intervention would not be significant. ${ }^{11}$

We found that patients transferred from peripheral centers had a higher probability of receiving delayed intervention (70.83\% of total referred cases) and hence associated with poor outcomes and more complications. This is comparable to studies demonstrating better fetal outcomes when decision to delivery interval is less than 20 minutes from onset of fetal bradycardia in cases of abruptio placentae. $^{12}$

Various studies advent vaginal delivery in grade I (mild abruption) and grade III (as fetal demise has already occurred). Aggressive use of volume expanders, fluid management with central venous pressure monitoring, timely blood transfusions and monitoring of vital parameters including urine output are essential while attempting vaginal delivery. Grade II requires expeditious delivery and hence if cervical factor is not favourable, delivery by LSCS is indicated. ${ }^{13,14}$ This is reflected in our study with $12.5 \%$ of cases being delivered vaginally, out of which $8.3 \%$ had intrauterine fetal death and in the remaining patients despite having grade II abruption, vaginal delivery was expected to occur within the next 30 minutes. The decision for LSCS has to be balanced carefully with the risk of coagulopathy due to intraoperative blood loss and adequate blood and products must be made available in such cases.

Madan and Puri demonstrated that patients with placental abruption were 8 times more likely to get admitted to intensive care units than other patients. ${ }^{15}$ Out of the patients receiving early intervention, $96.66 \%$ patients survived, out of which the patients who required intensive care of $<2$ days, with early extubation or ward care had no complications and hence a shorter hospital stay.

$40 \%$ of patients who received early intervention patients required prolonged ICU care of $>2$ days whereas amongst patients receiving delayed intervention, $83.33 \%$ survived and $66.66 \%$ patients required a longer intensive care stay with delayed extubation and subsequent longer hospital stay.

In a study conducted by Shrivastava and Kotur in a tertiary care center in Karnataka, major maternal complication seen was Shock, postpartum hemorrhage, altered coagulation profile and renal failure. In our study, the incidence of postpartum haemorrhage was not significantly lower in cases receiving early as compared to delayed care, however no cases receiving early care required a caesarean hysterectomy as compared to $11.1 \%$ patients receiving delayed care who required a caesarean hysterectomy due to post-partum haemorrhage. Similarly, the complication of surgical site infection and puerperal sepsis were not significantly lower in patients receiving early care however it must be kept in mind that presence of confounding factors could be responsible.

On the other hand, Acute Renal Failure, Shock, Massive Blood Transfusions and Coagulopathies were significantly more in patients receiving delayed intervention. Sher and Statland demonstrated that delivery should be completed within six to eight hours after the onset of placental abruption to avoid worsening of DIC and organ damage. This underscores the importance of early intervention to avoid the vicious cycle of coagulation defect, shock and end organ damage.

Maternal mortality has reduced from 122 in 2015-2017 to 113 in 2016-2018. However, India has missed the National Health Policy's target of reducing MMR to 100. World Health Organization's sustainable development goal is to reduce global MMR to less than 70 by 2030 . Abruptio placentae resulted in an overall $2.08 \%$ of maternal deaths in this study. There are studies from other developing countries where maternal mortality due to abruption ranges from $3-15 \% .^{16,17}$

Sheiner and Vardi demonstrated that pregnancies complicated with preterm placental abruption had 3 times higher rates of cord prolapse, non-reassuring fetal heart rate patterns, congenital malformations, cesarean deliveries, perinatal mortality and Apgar scores lower than 7 at $5 \mathrm{~min}$. In this study, Apgar score $<7$ and a longer duration of intensive care found to be more common in patients receiving delayed care, being $83.33 \%$ and $50 \%$, than those receiving early care.

A PNMR of 277.8 per 1000 in cases receiving delayed intervention as compared to cases receiving early intervention, 66.7 per 1000. In an American study by Ananth and Wilcox, PNMR related to abruption was found to be 119 per $1000 .^{18}$ It is essential to note here that low birth weight and prematurity are predictors and contributing factors to neonatal deaths and availability of comprehensive care for premature neonates significantly improves neonatal outcomes. In our study, out of the 3 neonatal deaths, 2 babies $(66.66 \%)$ were between the gestational age of 28-32 weeks and 1 (33.33\%) was between 32-36 weeks. Placental abruption is a risk factor for pre-mature deliveries and also independently an indicator of adverse fetal outcomes.

The limitation of this study was a small sample size and the possibility of onset of symptoms occurring significantly before the time of diagnosis. Thus multicentric studies with a larger sample size would help 
better define the minimum time interval between diagnosis and delivery with the best maternal and fetal outcomes.

\section{CONCLUSION}

If one sweats more in peace, one bleeds less during war. We have demonstrated that early intervention in abruptio placentae leads to better maternal and fetal outcomes. The culminative effort of government policies, health care systems and health workers is the proper execution of all means and methods available in order to reduce morbidity as well as mortality in all aspects of medicine for a more sustainable future.

Building more tertiary care institutes while strengthening of peripheral centers with timely initiation of resuscitative measures and shock management, availability of blood and blood products, better transportation facilities with proper education of medical as well as paramedical health care workers will be extremely beneficial in not only patient management but also in achieving long term goals.

Funding: No funding sources

Conflict of interest: None declared

Ethical approval: The study was approved by the Institutional Ethics Committee

\section{REFERENCES}

1. UNICEF. Health: maternal health. Available at: https://www.unicef.org/india/what-we-do/maternalhealth. Accessed on: 12 December 2020.

2. Calleja-Agius J, Custo R, Brincat MP. Placental abruption and placenta praevia. Eur Clinics Obstet Gynaecol. 2006;2:121-7.

3. Ananth CV, Keyes KM, Hamilton A, Gissler M, Wu C, Liu S, et al. An international contrast of rates of placental abruption: an age-period-cohort analysis. PLoS One. 2015;10:e0125246.

4. National Health Portal India. Diseases: antepartum haemorrhage. Available at: https://www.nhp.gov.in/disease/antepartumhemorrhage-bleeding-in-late-pregnancy. Accessed on: 12 December 2020.

5. Odibo AO. Pregnancy associated-plasma protein-a (PAPP-A) and alfa-fetoprotein (AFP) associated with placental abruption. Am J Obstet Gynecol. 2014;211(2):89-90.

6. Morgan T, Craven C, Lalouel JM, Ward K. Angiotensinogen Thr235 variant is associated with abnormal physiologic change of the uterine spiral arteries in first-trimester decidua. Am J Obstet Gynecol. 1999;180:95-102.

7. Harrington K, Cooper D, Lees C, Hecher K, Campbell S. Doppler ultrasound of the uterine arteries: the importance of bilateral notching in the prediction of pre-eclampsia, placental abruption or delivery of a small-for-gestational-age baby. Ultrasound Obstet Gynecol. 1996;7(3):182-8.

8. Sholl J. Abruptio placentae: Clinical management in non-acute cases. Am J Obstet Gynecol. 1987;156:40.

9. Sher G, Statland BE. Abruptio placentae with coagulopathy: A rational basis of management. Clin Obstet Gynecol. 1985;28:15.

10. Ananth CV, Wilcox AJ. Placental abruption and perinatal mortality in the United States. Am J Epidemiol. 2001;153(4):332-7.

11. Society for Maternal-Fetal Medicine (SMFM). Gyamfi-Bannerman C. Society for Maternal-Fetal Medicine (SMFM) Consult Series 44: Management of bleeding in the late preterm period. Am J Obstet Gynecol. 2018;218(1):2-8.

12. Kayani SI, Walkinshaw SA, Preston C. Pregnancy outcome in severe placental abruption. BJOG. 2003;110(7):679-83.

13. Knab DR. Abruptio placentae. An assessment of the time and method of delivery. Obstet Gynecol. 1978;52:625-9.

14. Page EW, King EB, Merrill JA. Abruptio placentae: dangers of delay in delivery. Obstet Gynecol. 1954;3:385-93

15. Madan I, Puri I, Jain NJ, Grotegut C, Nelson D, Dandolu V. Characteristics of obstetric intensive care unit admissions in New Jersey. J Maternal-Fetal Neonat Med. 2009;22(9):785-90.

16. Hossain N. Abruptio placenta and adverse pregnancy outcome. J Pak Med Assoc. 2010;60:443-6.

17. Dafallah SE, Babikir HE. Risk factors predisposing to abruptio placentae. Maternal and fetal outcome. Saudi Med J. 2004;25(9):1237-40.

18. Ananth CV, Wilcox AJ. Placental abruption and perinatal mortality in the United States. Am J Epidemiol. 2001;153(4):332-7.

Cite this article as: Mehta SP, Deshmukh PY, Bawa AK. Abruptio placentae: impact of early treatment on maternal and fetal outcomes. Int J Reprod Contracept Obstet Gynecol 2021;10:1533-9. 